\title{
17 \\ LEVERAGING FINANCE AND PRODUCING CAPITAL
}

ROB KITCHIN

\section{INTRODUCTION}

Ever since maps, gazetteers and almanacs have been created and traded there have been spatialised information economies. With the development of digital data from the 1950s on, the markets for spatial data and information have steadily diversified in products and exploded in volume of trade, with the growth of new market sectors for creating, processing and visualising spatial data such as geographic information systems (GIS) and computer-aided drafting (CAD), and new spatial information products such as geodemographics. This is particularly the case in the Web 2.0 era, with new forms of spatial media such as interactive digital maps, locative social media, city dashboards and augmented reality. Beyond state-produced or subvented forms of spatial media, such as city dashboards or internal or public GIS systems or open data systems, most spatial media are initiated, developed and owned by private, commercial interests. As such, whilst many might be deployed as free goods and services at the point of use (e.g. locative social media, some apps and most websites) they are ultimately concerned with leveraging and producing capital, covering their operating costs in terms of notfor-profit endeavours or turning a profit otherwise. In other words, the spatial media created have to be monetised in some way for continued operation.

Generally, the generation of capital can either be produced directly through the consumer purchase of the spatial media or the services provided through them (for a fixed fee or through a subscription), or indirectly through the sale of data generated through its use or derived data products, or through advertising (with adverts either being pushed to users or being embedded within the product, such as incorporating business details in base maps). Alternatively, the company might derive alternative value through the creation of new products, or through new insights that can be used to improve company 
efficiencies, productivity or competitiveness. In the case of open data initiatives, such as civic and community endeavours, university repositories or state agency-based initiatives, the product is expected to be free to use, yet the institution is unable to operate like a commercial enterprise, being reliant on state funding or philanthropy or subsidisation from research grants. One way or another then, developers of a spatial medium need to find a revenue stream to survive and to justify their investment of time and resources.

It is important then to recognise that finance and capital play an important role in all forms of spatial media: as funding and investment needed to ensure continued operation, and as profit that satisfies investors and shareholders and enables expansion. Moreover, spatial media operate within political economies and regulatory environments, their parameters of operation shaped by government programmes that support start-ups (e.g. state-supported accelerator and incubator programmes) and small- and medium-sized enterprises (SMEs) and multinationals (e.g. grants, subsidies, tax incentives and other forms of commercial state aid), tax regimes, laws, licensing and intellectual property regimes. Spatial media thus emerge and are deployed within economic, political and legal contexts. Their rollout also often leads to challenges to those contexts, for example, the generation of vast quantities of indexical geolocational data confronts data protection and minimisation legislation, and the rise of prosumption (wherein a user acts as both the producer and consumer of the data/service; Ritzer and Jurgenson, 2010) and the sharing economy (where people share or swap or collaborate/co-create resources without being directly employed or formally connected; Botsman and Rogers, 2010) threatens established employment practices and existing business models. This chapter examines some of the economics of spatial media and specifically how they are financed, how they are being used to produce capital, and how they are disrupting existing industries and creating new ones.

\section{SUSTAINING AND DISRUPTIVE INNOVATIONS}

Spatial media, in their diverse forms, constitute a significant economic sector. GIS and digital mapping are large multi-billion dollar industries consisting of a diverse ecosystem of companies from the large multinationals such as Esri that provide a range of software and services, through to SMEs that provide more specialist services. All kinds of economic sectors are now deploying spatial media, especially interactive maps, in their websites and apps to engage with customers, provide and source information, and to drive sales. For example, the property sales/rental, and travel, transport and logistics, sectors now rely heavily on online map-driven interfaces to enable customers to discover and explore potential new homes and guest accommodation and possible routes for travel, to book taxis, and to monitor the progress of commercial truck, van and car drivers. The Economist (2013) estimates that 3 million jobs in the USA depend on global positioning systems (GPS), a key cornerstone technology for many spatial media, especially those related to satnavs, logistic routers and locative apps on smartphones.

In many cases, the spatial media technologies being produced are sustaining innovations. That is, they provide a more efficient or productive way of performing a task but do not radically transform the work being undertaken. Here, spatial technologies such as GIS 
are used to produce better knowledge about assets, infrastructure, operations and markets, which is employed to facilitate greater coordination, planning and control within an organisation and to manage it more effectively, efficiently, competitively and productively, whilst reducing risks, costs and operational losses. Big spatial data gleaned from spatial media are leading to refinements in the products of the geodemographics industry, creating better insights into the spatialised makeup of customers and markets, helping to refine individual and place profiling and the spatial targeting of goods and services.

In other cases, spatial media are considered disruptive rather than sustaining innovations. That is, rather than maintaining the status quo of how an industry operates or how social relations are configured, they offer a more radical intervention that fundamentally challenges established ways of operating (Christensen, 1997). For example, once GIS became relatively inexpensive it severely disrupted traditional cartography by enabling the creation and querying of bespoke, layered maps in a timely fashion. More recently, the business models of traditional mapping agencies have been challenged by free-to-access services such as OpenStreetMap, and GIS has been disrupted by online mapping services such as Google Maps that provide free-to-access, interactive mapping. Spatial media sharing economy apps such as Uber and Hailo are radically altering how the taxi industry operates within the cities they operate, challenging industry regulation and leading to protests from existing companies and labour unions, who are still employing established technologies and employment practices (White, 2014). In some cases, spatial media, along with related technologies such as big data analytics, have led companies to fundamentally reorganise their structure, but also what the company specialises in. An example is IBM, who in the mid-2000s decided to disinvest from the production of hardware and networked systems and to re-orientate its business around analytics and consultancy, with its focus around what it termed 'Smarter Planet' initiatives.

In other cases, the technology being introduced is not sustaining or disrupting existing industries but is producing new products and services. Augmented reality and locative social media companies had no real equivalent prior to their founding. The spatial media that they produced therefore created an entirely new form of socio-spatial interaction. In the case of Foursquare this quickly scaled to an app that was used by millions of users around the globe (Evans, 2015). In the case of Google and Facebook it is over a billion users, though not all the data generated have a high spatial resolution (i.e. georeferenced with GPS coordinates), though the metadata include the internet protocol (IP) of the device, which provides some spatial information. As a free-to-use service, however, Foursquare's key issue beyond developing their product and building and maintaining a rapidly scaling user base was to devise a means to generate income.

\section{IF THE PRODUCT IS FREE, YOU ARE THE LABOUR AND THE PRODUCT}

Different types of spatial media initiatives have different sources and targets for revenue. For digital mapping companies it is selling a product such as maps or spatial data; for GIS companies it is selling software, consultancy and services; for the emerging 
sharing economy it is referral fees, the selling of services and monetising the data generated by users; and for locative social media it is advertising revenue and monetising user data. While all new ventures are precarious, the latter are particularly so given the lack of direct funding streams. As such, many spatial media start-ups are reliant on bank loans, angel investors and venture capital, or if they have floated on the stock market, shareholder investment, to stay afloat whilst they seek a sustainable revenue model. In many cases such a model might not be found. For every Google, Facebook, Airbnb and Uber that develops to become a multi-billion dollar company, there are thousands of companies and products that struggle and perish. For example, deVries et al. (2011) report that the average apps developer makes only US $\$ 3000$ per year from apps sales, with $80 \%$ of paid Android apps being downloaded fewer than 100 times. In addition, they note that even successful apps, such as MyCityWay, which had been downloaded 40 million times, did not generate profits, being sustained by venture capital. Indeed, it may well be that it will take time for new markets to develop and mature. For example, industries underpinned by GPS took many years to blossom after the decision to make the data openly available in 1984.

One of the key means through which many spatial media companies seek to stay afloat is by monetising the personalised data about individuals and companies that they generate. Indeed, the data that the users of their apps divulge - such as their location, personal photos, opinions, ratings, reviews, preferences, values and their network of social contacts -- are their key asset, potentially providing a rich insight into their lives, the places they visit and the products they consume. Rather than conduct expensive, sampled consumer surveys where respondents state where they would go and what they would do, such data can be directly harvested from locative social media revealing where all their users actually went and for what purposes, and how they rated the experience (Bollier, 2010). In this sense, a key business model for spatial media is what Zuboff (2015) terms 'surveillance capitalism' (see Chapters 20, 21 and 22). Moreover, the user of the media acts as a prosumer, providing the labour of generating some data at the same time as they are consuming the product. For example, on sites such as tripadvisor.com, prosumers rate and review hotels and other travel services whilst also consuming these volunteered data. The volume of reviews drives additional traffic to the site, generates advertising and referral revenue, and can have a marked influence on the choices of other travellers. It also provides useful data about the individual who volunteered the review, such as their lifestyle choices and travel spending. The insights of such prosumption are of high value to other companies meaning that the data can be monetised by selling them on to third parties such as data brokers (sometimes called data aggregators or consolidators or resellers), who add value by combining them with other data and performing analysis.

Data brokers capture, gather together and repackage data for rent (for one time use or use under licensing conditions) or resale. By assembling data from a variety of sources, including spatial media, data brokers can construct a vast relational data infrastructure that benefits from a 'data amplification' effect (Crampton et al., 2013); that is, data when combined enable far greater insights by revealing associations, relationships and patterns that remain hidden if the data remain isolated. The size of data holdings of these companies can be huge and is growing rapidly. For example, Epsilon is reputed to own data on 300 million company loyalty card 
members worldwide (Edwards, 2013). Acxiom is reputed to have constructed a databank concerning 500 million active consumers worldwide, with about 1500 data points per person, and claims to be able to provide a '360-degree view' on consumers (meshing offline, online and mobile data) (Singer, 2012). Other data broker and analysis companies include Alliance Data Systems, eBureau, ChoicePoint, Corelogic, Equifax, Experian, Facebook, ID Analytics, Infogroup, Innovis, Intelius, Recorded Future, Seisint and TransUnion.

Each company tends to specialise in different types of data and data products and services. Products include lists of potential customers/clients who meet certain criteria and consumer and place profiles; search and background checks; derived data products wherein brokers have added value through integration and analytics; and data analysis products that are used to micro-target advertising and marketing campaigns (by social characteristics and/or by location), guide the building of long-term customer relationships through personalised experiences, assess credit worthiness, socially and spatially sort individuals (e.g. shaping whether an individual is cultivated as a customer through incentives or whether a person gets a loan, or a tenancy or a job), provide tracing services, predictive modelling as to what individuals might do under different circumstances and in different places, or how much risk a person constitutes and supply detailed business analytics (CIPPIC, 2006; see Chapter 21). Moreover, such data can also be used to set the parameters for dynamic pricing and how much a person might expect to pay for goods and services given their profile.

The worry of some, including Edith Ramirez (2013), the chairperson of the Federal Trade Commission (FTC) in the USA, is that such firms practise a form of 'data determinism' in which individuals are not just profiled and judged on the basis of what they have done and where they live, but on the prediction of what they might do in the future. In other words, there is a worry that the data that spatial media and other technologies produce will precede their users, having all kinds of implications with regards to how they are treated by companies and the state (see Chapters 20, 21, and 22). Interestingly, given the volumes and diversity of personal and place-based data that spatial media produce, and that data brokers and analysis companies possess, and how the data are used to socially and spatially sort and target individuals and households, there has been remarkably little critical attention paid to their operations. Indeed, there is a dearth of academic and media analysis about such companies and the implications of their work and products.

\section{FINANCING OPEN ACCESS SPATIAL MEDIA}

As noted, many spatial media do not directly charge consumers (e.g. locative social media) and not all spatial media are commercial in orientation (e.g. many online GIS or city dashboards are produced by state agencies and universities, and many public service apps are state sponsored, and initiatives such as OpenStreetMap are voluntary, community initiatives). The challenge in these cases is to find an alternative means to finance the endeavour in the absence of directly charging for use. In the case of commercial endeavours, as discussed, the route pursued is usually to monetise the data and to sell additional services. The challenge for open access spatial media is 
more onerous as they adopt a different ethos that prioritises the public good (see Chapter 9). Open access in its purest form is 'digital, online, free of charge, and free of most copyright and licensing restrictions' (Suber, 2013). In other words, it seeks to remove both 'price barriers (subscriptions, licensing fees, pay-per-view fees) and permission barriers (most copyright and licensing restrictions)' (Suber, 2013) so that the spatial media and their associated data are freely available 'on the public internet' and can be used for 'any lawful purpose, without financial, legal, or technical barriers other than those inseparable from gaining access to the internet itself' (Budapest Open Access Initiative, 2002). As such, the data as well as the media are open access and cannot be monetised.

The conundrum for open access spatial media then is to find a way to deliver the technology and services with no or limited for-fee income. The solution has been the creation of a variety of open access positions that take varying stances on issues such as permission barriers, timing, and who pays and how for production, and the use of a variety of funding models. Different open access models include gratis open access (free of charge, but not free of copyright of licensing restrictions), libre open access (free of charge and expressly permits uses beyond fair use), delayed open access (paid access initially, becoming open after a set time period), green and gold open access (pay-for-production followed delayed publication in an open access repository or gratis open access) and so on (Suber, 2013). Kitchin et al. (2015) identify 14 different potential funding sources for funding open access endeavours, which they group into six classes (institutional, philanthropy, research, audience, service and volunteer; see Table 17.1).

Different types of open access projects use different combinations of these funding sources. For example, initiatives such as OpenStreetMap rely extensively on volunteered labour and philanthropic donations to fund their work. In contrast, a university initiative such as AIRO (All-Island Research Observatory; that provides online spatial data visualiz=sation of Irish public administration datasets) relies on core funding, research grants, consultancy and white-label development. The issue for all open access initiatives is that, beyond core state funding, the finance streams they rely on are cyclical and uncertain, and while often very worthy they find it difficult to raise and maintain continual funding, placing them under stress and threatening their existence. There is therefore a real question as to the sustainability of many open access spatial media initiatives and it will be interesting to observe how many will be continuing to operate in 10-15 years' time.

\section{ISSUES FOR FURTHER REFLECTION}

To date, much of the research and thinking about spatial media has focused on understanding the media themselves, their uses, their effects on individual spatial behaviour and knowledge, and how space and socio-spatial relations are surveilled and governed. There has been very little focus on the economic geographies of spatial media and how spatial media challenge existing social, political and economic contexts or established business models. Different forms of spatial media operate as both sustaining and disruptive innovations and are deeply implicated in 
TABLE 17.1 Models of funding open access spatial media

\begin{tabular}{|c|c|c|}
\hline & Model & Description \\
\hline \multirow[t]{4}{*}{ Institutional } & Core funded & $\begin{array}{l}\text { The state provides the core operational costs through a subvention } \\
\text { as with other state data services such as libraries, national archives, } \\
\text { statistical agencies, etc. }\end{array}$ \\
\hline & $\begin{array}{l}\text { Consortia } \\
\text { (membership) } \\
\text { model }\end{array}$ & $\begin{array}{l}\text { Build a consortium that collectively owns the data, pools labour, } \\
\text { resources and tools, and facilitates capacity building, but charges a } \\
\text { membership fee to consortium members to cover shared value- } \\
\text { added services }\end{array}$ \\
\hline & $\begin{array}{l}\text { Built in costs } \\
\text { at source }\end{array}$ & $\begin{array}{l}\text { When research grants are awarded by funders, applicants must } \\
\text { build in the costs for archiving the data and associated outputs in a } \\
\text { repository at the end of the project. This funding is transferred to } \\
\text { the repository for any services rendered }\end{array}$ \\
\hline & $\begin{array}{l}\text { Public/private } \\
\text { partnership }\end{array}$ & $\begin{array}{l}\text { Public/private partnerships, with the public sector providing the } \\
\text { data and private companies providing finance and value-added } \\
\text { services for access and re-use rights }\end{array}$ \\
\hline Philanthropy & $\begin{array}{l}\text { Philanthropy/ } \\
\text { corporate } \\
\text { sponsorship }\end{array}$ & $\begin{array}{l}\text { Funding is sourced from philanthropic organisations as grants, } \\
\text { donations, endowments and/or corporate sponsorship. If an } \\
\text { endowment is sizable then core services can be funded from } \\
\text { the interest. The donations can also be used to leverage other } \\
\text { funding, for example, matched money from the state. This can } \\
\text { also be reversed, so that state funding is used to try and leverage } \\
\text { philanthropic funding/corporate sponsorship }\end{array}$ \\
\hline Research & $\begin{array}{l}\text { Research } \\
\text { funded }\end{array}$ & $\begin{array}{l}\text { The majority of funding is generated through the sourcing of } \\
\text { research grants from national and international sources, with } \\
\text { overheads being used to subvent core services }\end{array}$ \\
\hline \multirow[t]{4}{*}{ Audience } & $\begin{array}{l}\text { Premium } \\
\text { product/ } \\
\text { service }\end{array}$ & $\begin{array}{l}\text { Offers end-users a high-end product or a service that adds value to } \\
\text { data (e.g. derived data, tools or analysis) for payment, either as fixed } \\
\text { payment, recurrent fees or pay-per-use, without using monopoly } \\
\text { rights. This enables the data producer to gain first-mover advantages } \\
\text { in the marketing and the sale of complementary goods }\end{array}$ \\
\hline & $\begin{array}{l}\text { Freemium } \\
\text { product/ } \\
\text { service }\end{array}$ & $\begin{array}{l}\text { Offers end-users a graded set of options, including a free-of-charge } \\
\text { option that includes basic elements (e.g. limited features or sampled } \\
\text { dataset), with more advanced, valuing adding options (e.g. special } \\
\text { formats, additional functionality, tools) being charged a fee. Opens up the } \\
\text { product/service to a wider, low-end market and more causal use, whilst } \\
\text { retaining paid, high-end product/service for more specialised users }\end{array}$ \\
\hline & $\begin{array}{l}\text { Content } \\
\text { licensing }\end{array}$ & $\begin{array}{l}\text { Make the data free for non-commercial re-use, but charge for-profit } \\
\text { re-users }\end{array}$ \\
\hline & $\begin{array}{l}\text { Infrastructural } \\
\text { razor and } \\
\text { blades }\end{array}$ & $\begin{array}{l}\text { An initial inexpensive or free trial is offered for products/services } \\
\text { (razor), which encourages take-up and continued paid use (blades). } \\
\text { It might be that access is free through application programming } \\
\text { interfaces (APIs), but that computational usage is charged on a pay- } \\
\text { as-you-go model, with the latter cross-subsidising the former }\end{array}$ \\
\hline
\end{tabular}




\begin{tabular}{|c|c|c|}
\hline & Model & Description \\
\hline \multirow[t]{3}{*}{ Service } & $\begin{array}{l}\text { Pay per } \\
\text { purpose }\end{array}$ & $\begin{array}{l}\text { Charge for services beyond data use, such as ingest, archiving, } \\
\text { consulting and training services }\end{array}$ \\
\hline & $\begin{array}{l}\text { Free with } \\
\text { advertising }\end{array}$ & $\begin{array}{l}\text { Products/services are provided for free, but users receive } \\
\text { advertising when using the product/service (revenue generating) } \\
\text { or the products/services are provided by different companies and } \\
\text { branded as such to encourage use of their other products/services } \\
\text { (cross-subsidisation) }\end{array}$ \\
\hline & $\begin{array}{l}\text { White-label } \\
\text { development/ } \\
\text { platform } \\
\text { licensing }\end{array}$ & $\begin{array}{l}\text { A customised product/service is created for a client and branded } \\
\text { for their use, with that client paying a one-off fee or subscription } \\
\text { that includes maintenance and update costs }\end{array}$ \\
\hline Volunteer & Open source & $\begin{array}{l}\text { Offers end-users data products/services for free, with the } \\
\text { infrastructure maintained on a voluntary basis, including } \\
\text { crowdsourcing }\end{array}$ \\
\hline
\end{tabular}

Source: Kitchin et al. (20I5). Assembled from Ferro and Osella (20I3); Maron (20I4); consultation with Digital Repository of Ireland stakeholders and team discussion.

the emergence of the new sharing economy, as well as economic sectors such as data brokerage, security and surveillance. As yet, however, we have little empirical understanding or detailed theoretical knowledge of the ways in which spatial media create and sustain disruption in relation to business models, company organisation and operation, labour practices, markets, consumption and regulatory oversight. Nor do we know how these disruptions might vary between different forms of spatial media, or how they are unfolding in different places as a function of varying culture, governance, legislation and political economies. Moreover, we know little about the geography of spatial media production -- for example, are there agglomerations of spatial media industries, and are they similar to related industries such as software production more generally? Are there global divisions of labour in the production of spatial media? In short, there is a real need to conduct economic geographies of spatial media.

Further, as discussed in Chapters 20, 21 and 22, there is also a need to examine in more detail the social and political implications of the economics associated with spatial media. Whilst the sharing economy is often lauded as a new gift economy that promotes collaboration and community building, it has also been critiqued as being co-opted by market capitalism as a way of accessing volunteered labour and casualising labour and circumventing some of the costs of doing business such as avoiding taxes, regulations and insurance. Data brokers gather up huge quantities of spatial media data, conjoin them with other data, and apply analytics that profile, target, and socially sort individuals and places. They are little regulated and are not required by law to provide individuals access to the data held about them, nor are they obliged to correct errors relating to those individuals. The data industry then raises all kinds of ethical questions about privacy, how its work affects people and how it might be regulated in an age where data production is ubiquitous. The move 
to create open access spatial media, either as state endeavours or as volunteered, crowdsourced initiatives, is not straightforward. While the spatial media represent a public good, there are still associated costs with their production that need to be financed and there are knock-on consequences in making data open for established data providers. As such, there is a more complicated set of political, social and economic implications associated with open access than many of its proponents would acknowledge (see Kitchin, 2014). In short, a whole series of studies is required concerning the implications of the new economies produced by spatial media and how regulations should be altered to minimise their more pernicious effects.

\section{ACKNOWLEDGEMENTS}

The research for this chapter and book was funded by a European Research Council Advanced Investigator grant, The Programmable City (ERC-2012-AdG-323636).

\section{REFERENCES}

Bollier, D. (2010) The Promise and Peril of Big Data. Aspen, CO: The Aspen Institute. Available at: http://www.aspeninstitute.org/sites/default/files/content/docs/pubs/ The_Promise_and_Peril_of_Big_Data.pdf (accessed 27 July 2016).

Botsman, R. and Rogers, R. (2010) What's Mine Is Yours: The Rise of Collaborative Consumption. New York: Harper Business.

Budapest Open Access Initiative (2002) 'Read the Budapest Open Access Initiative'. Available at: http://www.budapestopenaccessinitiative.org/read (accessed 27 July 2016).

Christensen, C.M. (1997) The Innovator's Dilemma. Cambridge, MA: Harvard Business Review Press.

CIPPIC (2006) 'On the data trail: how detailed information about you gets into the hands of organizations with whom you have no relationship. A report on the Canadian Data Brokerage Industry'. Ottawa: The Canadian Internet Policy and Public Interest Clinic.Available at: https://cippic.ca/sites/default/files/May1-06/DatabrokerReport. pdf (accessed 11 August 2016).

Crampton, J., Graham, M., Poorthuis, A., Shelton, T., Stephens, M., Wilson, M.W. and Zook, M. (2013) 'Beyond the geotag? Deconstructing "Big Data" and leveraging the potential of the geoweb', Cartography and Geographic Information Science, 40(2): $130-9$.

deVries, M., Kapff, L., Negreiro Achiaga, M., Wauters, P., Osimo, D., Foley, P., Szkuta, K., O'Connor, J. and Whitehouse, D. (2011) 'Pricing of Public Sector Information Study (POPSIS)'. Available at: http://ec.europa.eu/newsroom/dae/document.cfm?doc_ id=1158 (accessed 11 August 2016).

Edwards, J. (2013) 'Facebook is about to launch a huge play in 'Big Data' analytics', Business Insider, 10 May. Available at: http://www.businessinsider.com/facebook-isabout-to-launch-a-huge-play-in-big-data-analytics-2013-5 (accessed 27 July 2016).

Evans, L. (2015) Locative Social Media: Place in the Digital Age. London: Palgrave. 
Ferro, E. and Osella, M. (2013) 'Eight business model archetypes for PSI re-use. Open data on the web', Workshop, 23-24 April 2013, Google Campus, Shoreditch, London. Available at: http://www.w3.org/2013/04/odw/odw13_submission_27.pdf (accessed 27 July 2016).

Kitchin, R. (2014) The Data Revolution: Big Data, Open Data, Data Infrastructures and Their Consequences. London: Sage.

Kitchin, R., Collins, S. and Frost, D. (2015) 'Funding models for open access digital data repositories', Online Information Review, 39 (5): 664-81.

Maron, N. (2014) 'A guide to the best revenue models and funding sources for your digital resources', Ithaka S+C and JISC. Available at: https://www.jisc.ac.uk/reports/ the-best-revenue-models-and-funding-sources-for-your-digital-resources (accessed 27 July 2016).

Rameriz, E. (2013) 'The privacy challenges of big data: a view from the lifeguard's chair', Technology Policy Institute Aspen Forum, 19 August. Available at: https://www.ftc. gov/sites/default/files/documents/public_statements/privacy-challenges-big-dataview-lifeguard\%E2\%80\%99s-chair/130819bigdataaspen.pdf (accessed 27 July 2016).

Ritzer, G. and Jurgenson, N. (2010) 'Production, consumption, prosumption: the nature of capitalism in the age of the digital "prosumer", Journal of Consumer Culture, 10(1): $13-36$.

Singer, N. (2012) 'You for sale: mapping, and sharing, the consumer genome', New York Times, 17 June.Available at: http://www.nytimes.com/2012/06/17/technology/acxiomthe-quiet-giant-of-consumer-database-marketing.html (accessed 27 July 2016).

Suber, P. (2013) ‘Open access overview’.Available at: http://legacy.earlham.edu/ peters/ fos/overview.htm (accessed 27 July 2016).

The Economist (2013) 'Open data: a new goldmine', The Economist, 18 May. Available at: http://www.economist.com/news/business/21578084-making-official-data-publiccould-spur-lots-innovation-new-goldmine (accessed 27 July 2016).

White, J. (2014) 'Hailo, Uber and the deregulation of Ireland's taxi industry', Programmable City blog, 11 June 11. Available at: http://www.maynoothuniversity.ie/ progcity/2014/06/hailo-uber-and-ireland/ (accessed 27 July 2016).

Zuboff, S. (2015) 'Big other: surveillance capitalism and the prospects of an information civilization', Journal of Information Technology, 30: 75-89. 